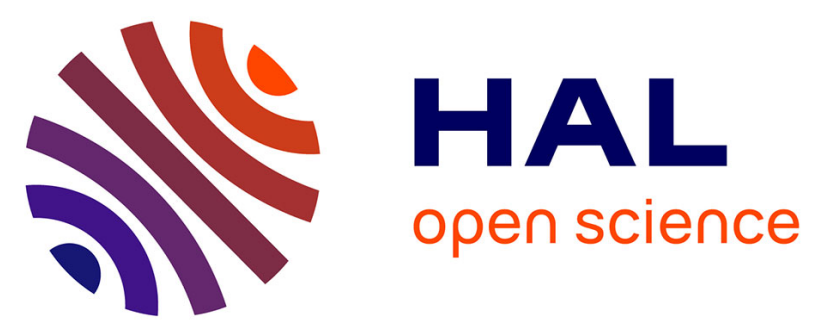

\title{
Incorporation of Organomodified Layered Silicates and Silica in Thermoplastic Elastomers in Order to Improve Tear Strength
}

\author{
Olivier Jaudouin, Jean-Jacques Robin, Didier Perrin, Rodolphe Sonnier, \\ Patrick Ienny, Romain Leger, José-Marie Lopez-Cuesta
}

\section{To cite this version:}

Olivier Jaudouin, Jean-Jacques Robin, Didier Perrin, Rodolphe Sonnier, Patrick Ienny, et al.. Incorporation of Organomodified Layered Silicates and Silica in Thermoplastic Elastomers in Order to Improve Tear Strength. INCORPORATION OF ORGANOMODIFIED LAYERED SILICATES AND SILICA IN THERMOPLASTIC ELASTOMERS IN ORDER TO IMPROVE TEAR STRENGTH, Jun 2011, Paris, France. pp.217-227, 10.4028/www.scientific.net/MSF.714.217 hal-00797960

\section{HAL Id: hal-00797960 https://hal.science/hal-00797960}

Submitted on 3 Nov 2020

HAL is a multi-disciplinary open access archive for the deposit and dissemination of scientific research documents, whether they are published or not. The documents may come from teaching and research institutions in France or abroad, or from public or private research centers.
L'archive ouverte pluridisciplinaire HAL, est destinée au dépôt et à la diffusion de documents scientifiques de niveau recherche, publiés ou non, émanant des établissements d'enseignement et de recherche français ou étrangers, des laboratoires publics ou privés. 


\title{
INCORPORATION OF ORGANOMODIFIED LAYERED SILICATES AND SILICA IN THERMOPLASTIC ELASTOMERS IN ORDER TO IMPROVE TEAR STRENGTH
}

\author{
Olivier Jaudouin ${ }^{1, a}$, Jean-Jacques Robin ${ }^{2, b}$, Didier Perrin ${ }^{1, c}$, \\ Rodolphe Sonnier ${ }^{1, \mathrm{~d}}$, Patrick lenny ${ }^{1, \mathrm{e}}$, Romain Léger $^{1, \mathrm{f}}$, \\ José-Marie Lopez-Cuesta ${ }^{1, g}$ \\ ${ }^{1}$ Centre des Matériaux de Grande Diffusion, Ecole des Mines d'Alès - 6 Avenue de Clavières - \\ 30319 Alès Cedex, France \\ ${ }^{2}$ Charles Gerhardt Montpellier UMR5253 CNRS-UM2-ENSCM-UM1 - Equipe Ingénierie et \\ Architectures Macromoléculaires, Université Montpellier II - Bat 17 - cc1702, Place Eugène \\ Bataillon 34095 - Montpellier Cedex 5
}

aOlivier.Jaudouin@mines-ales.fr, 'bJean-Jacques.Robin@univ-montp2.fr, 'Didier.Perrin@minesales.fr, ${ }^{\mathrm{d}}$ Rodolphe.Sonnier@mines-ales.fr, ${ }^{\mathrm{e}}$ Patrick.lenny@mines-ales.fr, ${ }^{\mathrm{f}}$ Romain.Leger@mines-

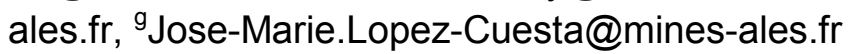

Keywords: Organomodified layered Silicates, SEBS, polyurethane, tear strength, tensile tests

\begin{abstract}
Organomodified layered silicates and silicas have been incorporated in thermoplastic elastomers such as styrene-ethylene-butylene-styrene copolymers (SEBS) and polyurethanes (PU) in order to improve mechanical properties - especially tear strength. The organically modified layered silicates used were Cloisite ${ }^{\circledR} 30 \mathrm{~B}$, a montmorillonite modified with a ternary ammonium salt with hydroxyls as end groups and Nanofil ${ }^{\circledR} 2$ which is organically modified by long chains of hydrocarbon and benzyl groups. Sepiolite, a natural clay with fibrous morphology was also used. The silicas incorporated are Aerosil 300, hydrophilic fumed silica and Aerosil R202, hydrophobic fumed silica. Nano-particles are incorporated between 1 and 5 weight percent. A compatibilizer SEBS grafted with maleic anhydride has been incorporated in some of the formulations for a better dispersion of some of the nano-particles. Different ways of incorporation have been investigated. For SEBS formulations, melt blends of SEBS pellets and clays have been prepared with an internal mixer and then films have been casted. For polyurethanes, solvent blending of polyols and clays were carried out in a vessel and then, compression molding of the blend with diisocyanates was made to synthesize polyurethanes. Materials have been compared on the basis of normalized tear test and sequenced tensile test. Mechanical parameters, as stabilization ratio (Mullins effect) and viscoelastic ratio, have been defined by integration of the stress-strain curves obtained. An interesting improvement of tear strength was observed for modified materials.
\end{abstract}

Introduction. Thermoplastic elastomers such as polyolefin copolymers and polyurethane elastomers are outstanding materials with a lot of applications. Hence, they received a widespread attention since they have been discovered [1-5]. Most of these researches aimed the improvement of elastic properties and the increase of Young's modulus for applications such as rigid materials or soft structural materials. Few of them combined high elastic properties, high elongation at break and a low Young's modulus. 
Styrene - Ethylene/Butylene - styrene copolymers (SEBS) belong to these materials which can be designed to impart very high elastic elongation with low modulus. They are based on the phase separation of rigid polystyrene blocks and a soft polyethylene and polybutylene rubber. The styrene blocks act as cross-linking nodules and give the elastomeric properties of the material. Formulations with low polystyrene contents (about 10 weight percent) and a quite high proportion of butylene units compared to ethylene ones in the rubber lead to the required set of properties. Butylene units enable a decrease of cristallinity of rubber phase as well as the decrease of soft phase glass transition leading to the increase of softness and elongation of the material. Styrene blocks enhance the elastic properties of the material even at low proportions. Polyurethane (PU) elastomers can also be designed to impart these properties. The cross-linking nodules are here the urethane units and the diisocyanate monomers, while the soft phase is the polyol monomers. Diisocyanates such as methylene diphenyl diisocyanate which can rotate around the carbon of the methylene and long polyols such as hydroxytelechelic polybutadienes bring high elongation with rather good elasticity. However, these materials impair strength and lead to very low tear strength.

Various studies [6-12] report the use of little amount of nano-particles in elastomers to improve stiffness as well as tear strength. The incorporation of intercalated or exfoliated layered silicates such as organomodified montmorillonites and sepiolites or organomodified silica can lead to local stress concentrations able to stop crack propagation when meeting a nano-particle. These effects lead to a global improvement of tear strength. Most of the studies report a decrease of elongation at break with the use of nano-particles. Nevertheless, some of them show an enhancement of this mechanical property when nano-particles are well dispersed and linked to the polymer backbone [10-12]. In order to enhance the effect of some organophilic nano-particles, a compatibilizer has also been incorporated as reported in some studies [13-14].

The aim of this study is to improve the tear strength of the SEBS and Polyurethane materials by adding nano-particles without decreasing the initial properties such as high elongation at break, high elasticity and low flow stress. The mechanical properties are investigated by means of two tests: tear strength and sequenced tensile tests, which are able to characterize elasticity and elongation at break. The designed materials are intended to show soft hyperelastic properties: very high elongation at break, high elasticity and low stress flow.

Materials. SEBS Themoflex $10 \mathrm{H} 730$ it is a very soft SEBS (11 Shore A) with high elongation at break, high elasticity and low modulus was purchased at plastic technology service LTD, SEBS-gMA Kraton FG1901X was purchased at Shell. The ratio of maleic anhydride is $2 \mathrm{wt} \%$. Methylene diphenyl diisocyanate (MDI) and dibutyltin dilaurate (DBTDL) were purchased at Sigma-Aldrich. Hydroxtelechelic polybutadiene (PBHT) $(10000 \mathrm{~g} / \mathrm{mol})$ was kindly supplied by Sartomer.

Sepiolite Pangel S9, a high purity sepiolite was also kindly supplied by Tolsa. Cloisite ${ }^{\circledR} 30 \mathrm{~B}$ and Nanofil ${ }^{\circledR} 2$ montmorillonites were purchased at Rockwood. Cloisite ${ }^{\circledR} 30$ B is organomodified by a methyl, tallow, bis-2-hydroxyethyl, quartenary ammonium and Nanofil@2 by a long-chain hydrocarbon and a benzyl group. Aerosil ${ }^{\circledR} 300$ and Aerosil ${ }^{\circledR}$ R202 were supplied by Evonik, Aerosil ${ }^{\circledR} 300$ is a hydrophilic fumed silica with a BET surface area of $300 \pm 30 \mathrm{~m}^{2} / \mathrm{g}$ and Aerosil ${ }^{\circledR}$ R202 is a hydrophobic fumed silica with a BET surface area of $100 \pm 20 \mathrm{~m}^{2} / \mathrm{g}$.

Preparation. SEBS-based masterbatches were made in an internal mixer at $150^{\circ} \mathrm{C}, 60 \mathrm{rpm}$ during 15 minutes: Fillers and SEBS-g-MA were incorporated in SEBS matrix at levels of 10 or $20 \mathrm{wt} \%$. These masterbatches were then diluted in a twin screw extruder in order to disperse and intercalate or exfoliate nano-particles at $170^{\circ} \mathrm{C}$. Finally, the materials were casted as films with a cast extruder at a thickness of $0.6 \mathrm{~mm}$.

Polyurethane-based formulations were processed by another way. Nanoclays were mechanically dispersed in the polyol (PBHT) in a vessel with a mechanical stirrer. Three drops of dibutyltin dilaurate (catalyst) and MDI was then added. The ratio diisocyanate/polyol was set at 1.1 because previous studies that we realized showed that it was the best compromise for low modulus and high elongation at break, (the polyurethane alone is called PU1.1). The mix was heated in an oven at $80^{\circ} \mathrm{C}$ in order to melt MDI, afterwards the mix was sheet-shaped in a thermocompression press at 
$80^{\circ} \mathrm{C}$ under 120 bars during 10 minutes. It is necessary to incorporate nano-particles in the polyol before addition of MDI to disperse them otherwise reaction takes place before the casting and viscosity increases.

Table 1 presents the different formulations performed and tested mechanically.

Table 1. Formulations of the study

\begin{tabular}{|c|c|c|c|c|c|c|c|c|}
\hline Formulation & $\begin{array}{c}\text { SEBS } \\
\text { Thermoflex } \\
10 \mathrm{H} 730\end{array}$ & PU1.1 & $\begin{array}{c}\text { SEBS -g-MA Kraton } \\
\text { FG 1901X }\end{array}$ & $\begin{array}{l}\text { Sepiolite } \\
\text { Pangel S9 }\end{array}$ & $\begin{array}{c}\text { Cloisite } \\
\text { 30B }\end{array}$ & Nanofil2 & $\begin{array}{c}\text { Silica } \\
\text { Aerosil } \\
\text { R202 }\end{array}$ & $\begin{array}{c}\text { Silica } \\
\text { Aerosil } 300\end{array}$ \\
\hline 1 & 99 & 1 & 1 & 1 & 1 & I & 1 & 1 \\
\hline 2 & 97 & 1 & 1 & 3 & 1 & I & 1 & 1 \\
\hline 4 & 99 & 1 & 1 & 1 & 1 & 1 & 1 & 1 \\
\hline 5 & 97 & 1 & 1 & 1 & 3 & 1 & 1 & 1 \\
\hline 7 & 99 & 1 & 1 & 1 & 1 & 1 & 1 & 1 \\
\hline 8 & 97 & 1 & 1 & 1 & 1 & 3 & 1 & 1 \\
\hline 10 & 99 & 1 & 1 & 1 & 1 & 1 & 1 & 1 \\
\hline 11 & 97 & 1 & 1 & 1 & 1 & 1 & 3 & 1 \\
\hline 13 & 91 & 1 & 8 & 1 & 1 & 1 & 1 & 1 \\
\hline 14 & 91 & 1 & 8 & 1 & 1 & 1 & 1 & 1 \\
\hline 15 & 1 & 99 & 1 & 1 & 1 & I & 1 & 1 \\
\hline 16 & 1 & 97 & 1 & 1 & 3 & 1 & / & / \\
\hline
\end{tabular}

Morphological analysis. SEM pictures were carried out on the different formulations and XRD scans were carried out on formulations containing montmorillonites. The size of interlayers can be measured thanks to the XRD scans. These scans show if the montmorillonite is intercalated with polymer or even exfoliated.

\section{Mechanical tests}

Tear strength tests. Tear strength tests have been carried out according to ISO 34- 1 standard, with an angular test unnotched specimen. Figure 1 shows the shape of the test specimen, the dimensions are given in millimeters. The tear strength expressed in $\mathrm{kN} / \mathrm{m}$ is calculated by the maximum force necessary to break the specimen in $\mathrm{N}$ divided by the thickness of the specimen in $\mathrm{mm}$. The test is realized at a speed of $500 \mathrm{~mm} / \mathrm{min}$.

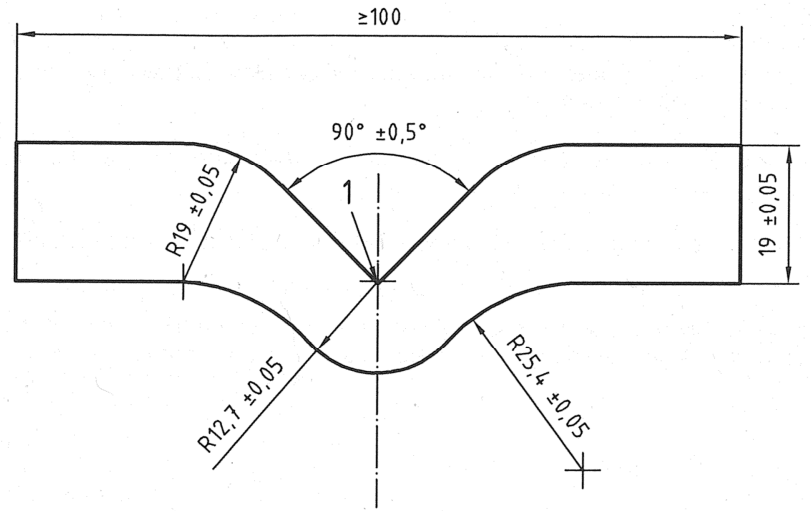

Figure 1. Shape of the angular test specimen

Sequenced tests. This test is quite similar to a fatigue test. The elastomer sheet or film were cut into rectangular strips of width $15 \mathrm{~mm}$, and tested in uniaxial tension with $30 \mathrm{~mm}$ between the grips. Extension was measured by the clamp displacements. The test consisted of eight load-unload cycles 
to a maximum strain of $150 \%$. Then, the specimens were tested up to fracture at the last loading step. From the stress-strain data obtained specific work input $W$, obtained by the integration were measured. In order to characterize viscoelastic and stabilization properties, two parameters were considered. The first parameter is the relative stabilization ratio (SR) given in percent and obtained by integration over the first load step $\left(W_{1}\right)$, from which is substracted the last load step $\left(W_{8}\right)$. The result obtained is normalized by the first work input $\left(W_{l}\right)$. The second parameter defines the dissipated work due to the viscoelasticity given by the viscoelastic ratio $(V R)$ : It is obtained by dividing the integration between the last load and unload sequence (eighth hysteresis $\left(H_{8}\right)$ ) and the work obtained by integration over the last load step $\left(W_{8}\right)$. Formulae are given in Equations 1 and 2 and the Figures 1 and 2 show the areas used for the calculations for the stabilization ratio and the viscoelasticity ratio respectively.

$$
\begin{gathered}
\% S R=\frac{W_{1}-W_{8}}{W_{1}} * 100 \\
\% V R=\frac{H_{8}}{W_{8}} * 100
\end{gathered}
$$

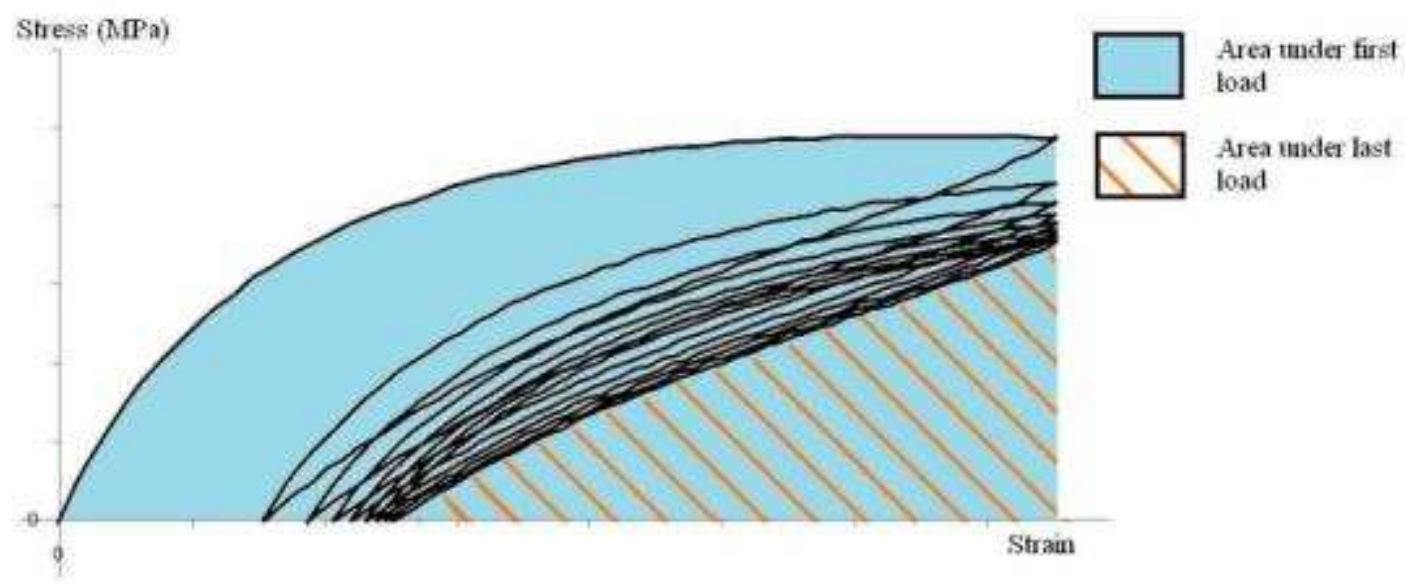

Figure 2. Areas under the curve for calculation of $\% \mathrm{SR}$

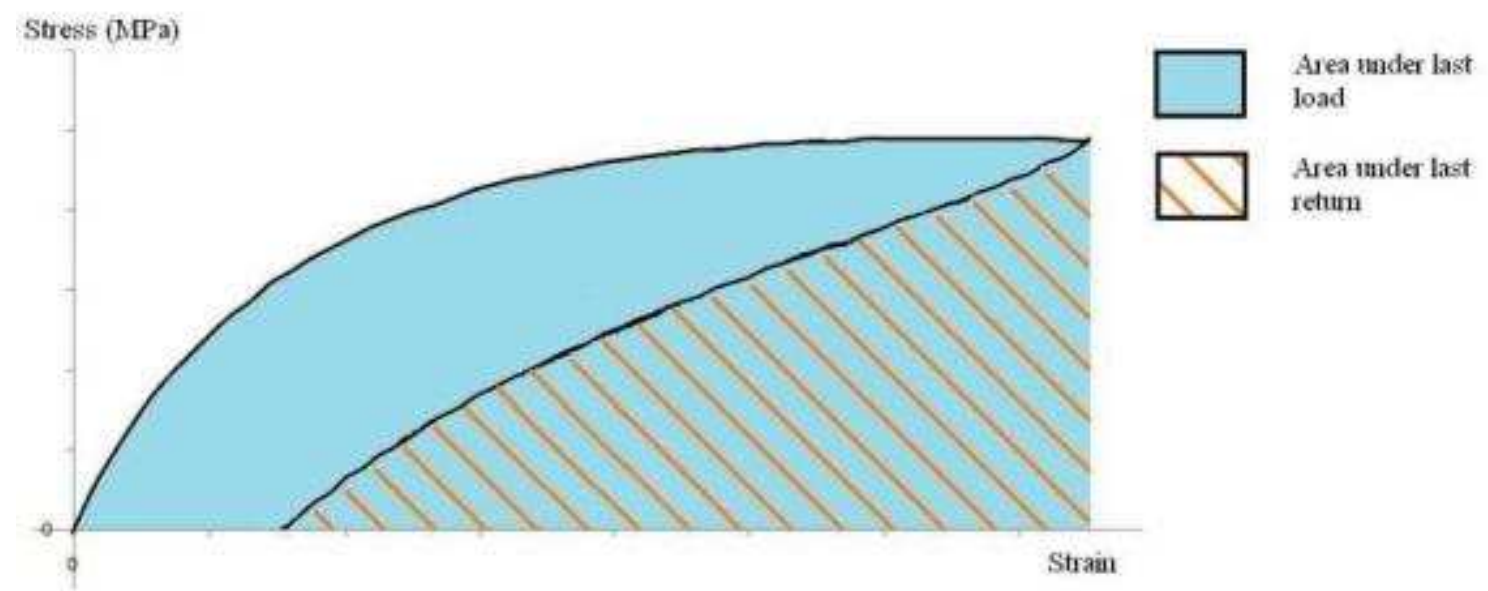

Figure 3. . Areas under the curve for calculation of $\% \mathrm{VR}$ 
$\% S R$ characterizes the well-known Mullins effect which associates a strong stiffness reduction (stress-softening) to the enhancement of the residual strain. The more stable the material, the lower $\%$ stabilization is. The aim for our materials is a low $\% S R$, it means that the elastomer does not lose its initial properties and so that the Mullins effect is low.

$\% V R$ quantifies the efficiency of the material to return instantly to its initial position after a loadunload sequence. This parameter is important for an intended application which necessitates a purely elastic response. We decided to measure it in the last cycle once the material is stabilized. The ideal result would be a low $\% V R$ to ensure a quasi-elastic behavior of the material.

\section{Results.}

Morphological analysis. SEM pictures and XRD scans of SEBS filled with different nanoparticles are presented in the following figures.
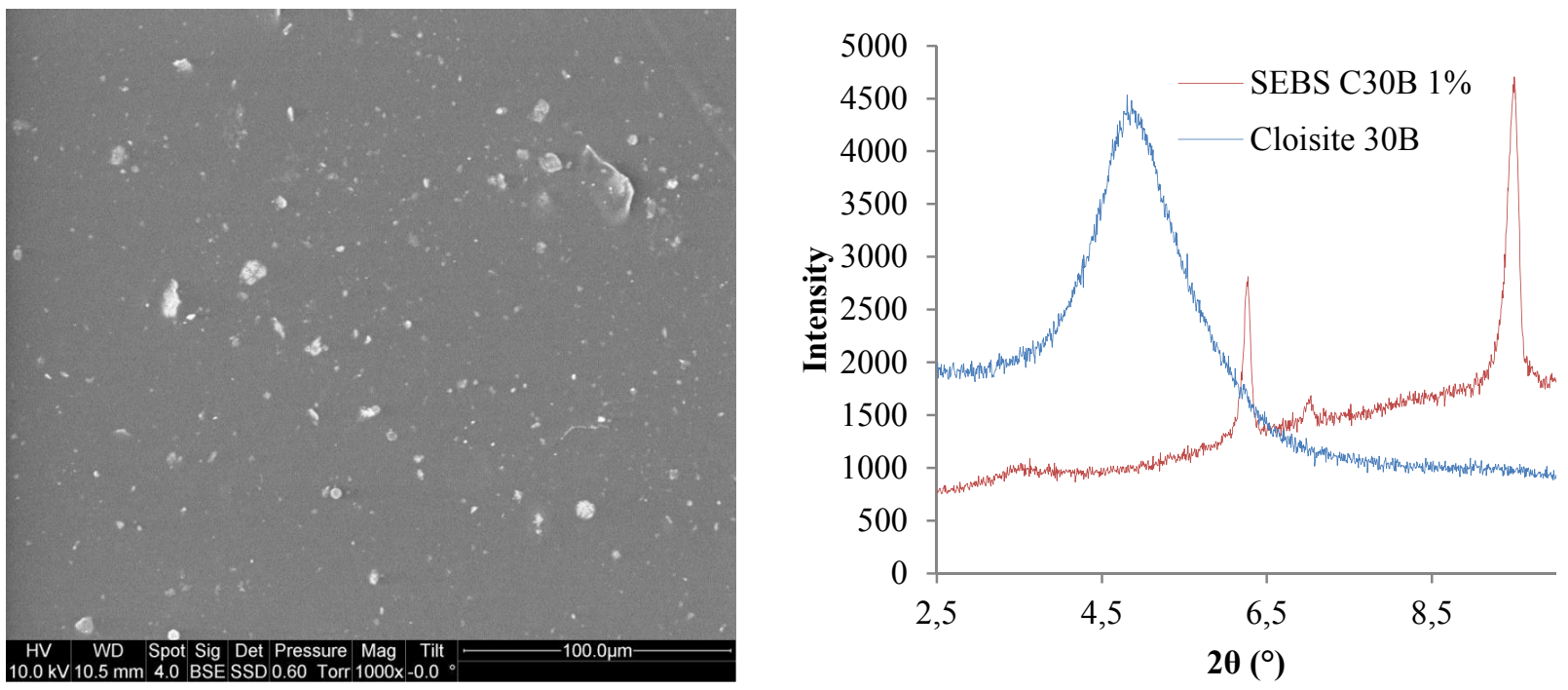

Figure 4. SEM pictures and XRD scans of SEBS / Cloisite ${ }^{\circledR} 30 \mathrm{~B}(1 \mathrm{wt} \%)$
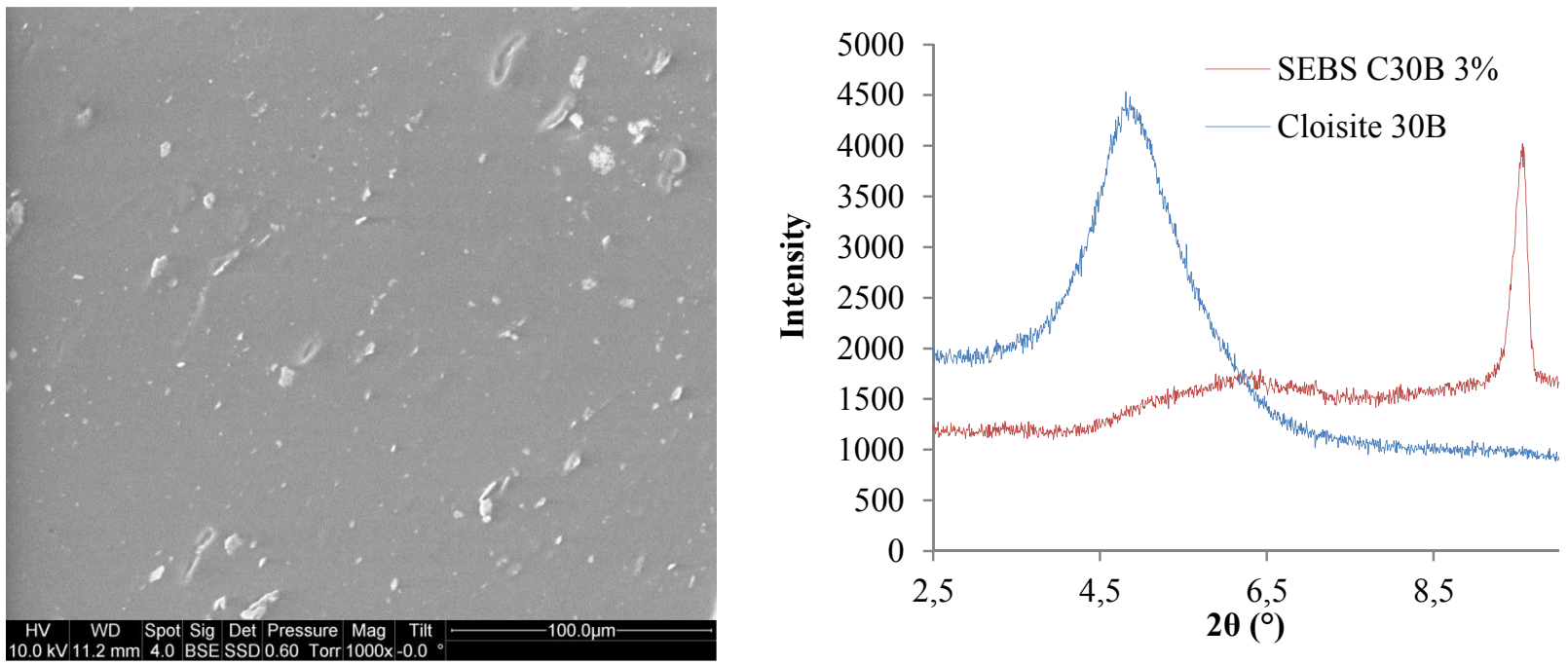

Figure 5. SEM pictures and XRD scans of SEBS / Cloisite ${ }^{\circledR} 30 B(3 \mathrm{wt} \%)$

Cloisite ${ }^{\circledR} 30 \mathrm{~B}$ seems to be much better dispersed when incorporated at $1 \mathrm{wt} \%$ than at $3 \mathrm{wt} \%$ : the size of particles is lower. There are fewer aggregates at this lower level of incorporation. XRD scans show that the peak of Cloisite ${ }^{\circledR}$ 30B disappears in the two formulations meaning that they are exfoliated in both of them. Meanwhile, it is possible that the levels of incorporation are too low to observe this peak. 

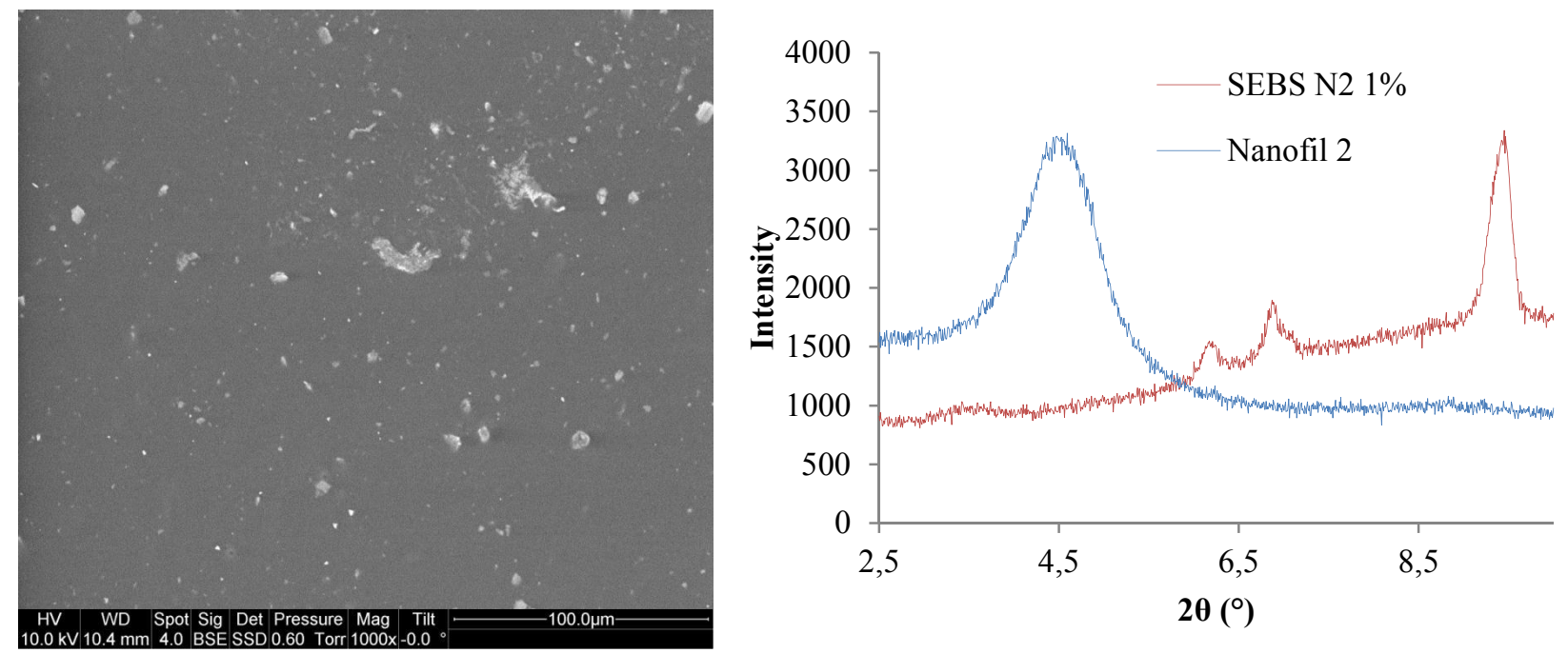

Figure 6. SEM pictures and XRD scans of SEBS / Nanofil@ $2(1 \mathrm{wt} \%)$
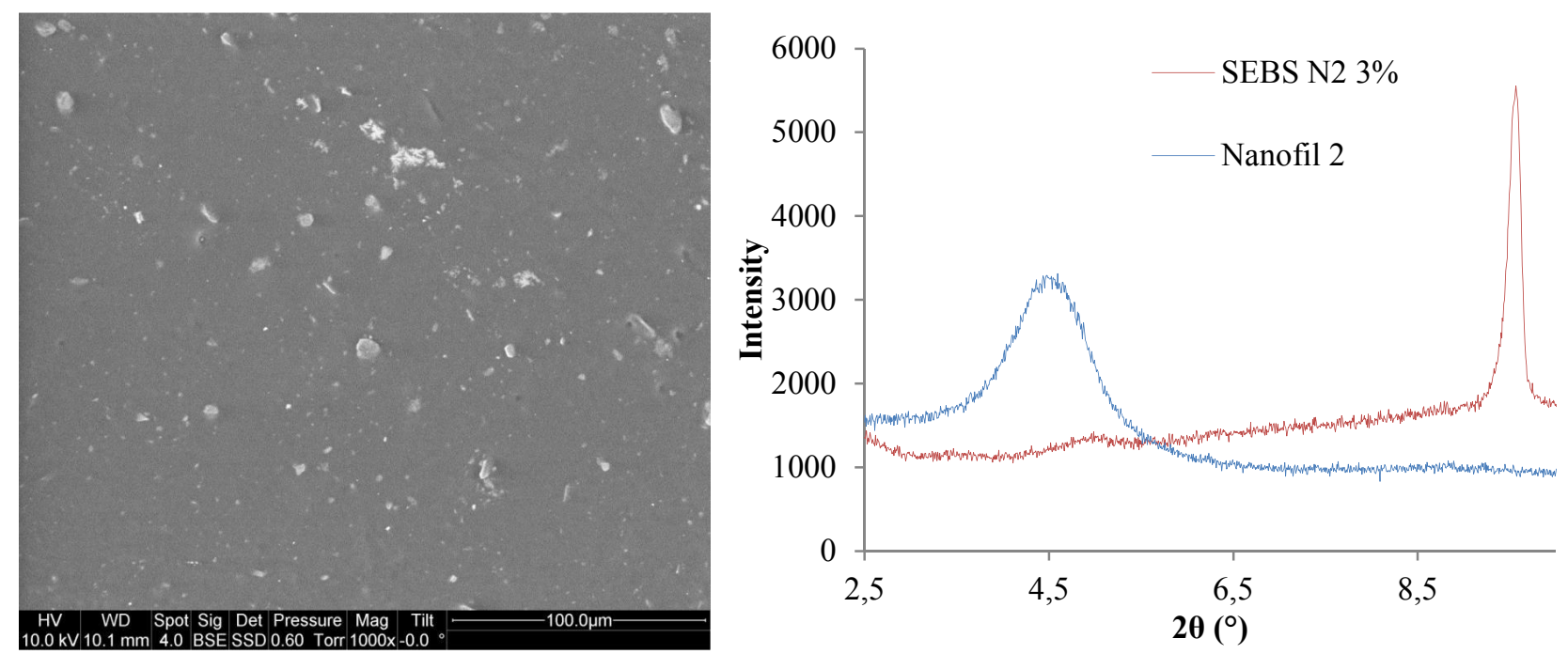

Figure 7. SEM pictures and XRD scans of SEBS / Nanofil@ $2(3 \mathrm{wt} \%)$

In both formulations of SEBS with Nanofil ${ }^{\circledR} 2$, it seems that the filler is not well dispersed. There are big aggregates of more than 10 microns. Even if XRD scans do not show any peak of Nanofil ${ }^{\circledR}$ 2 in the formulations meaning that clays are exfoliated, dispersion is not good. 


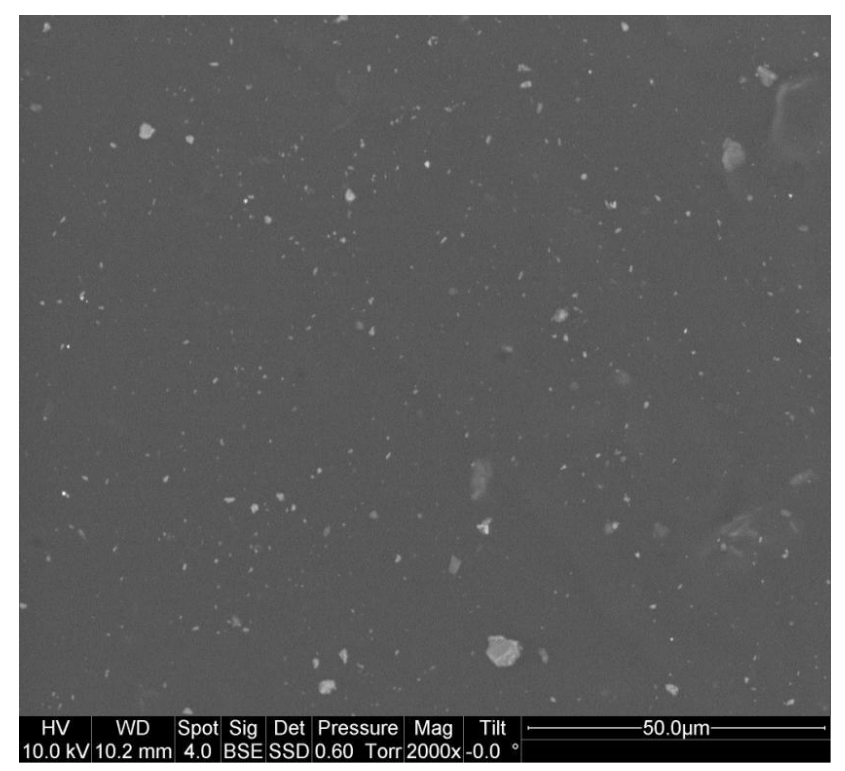

(a)

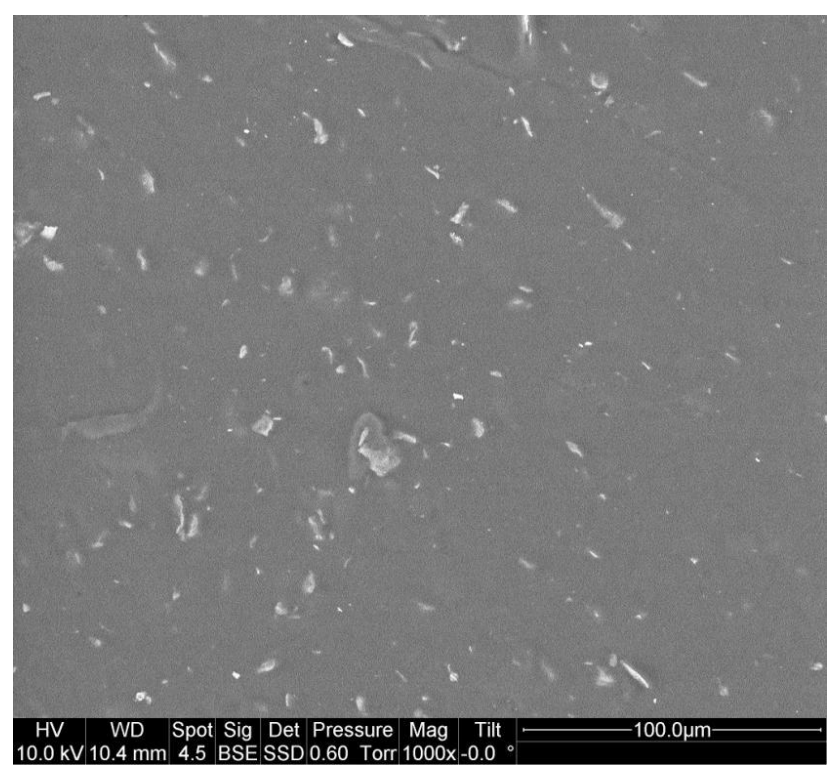

(b)

Figure 8. SEM pictures of SEBS / Sepiolite S9 (a: 1 wt\% ) (b: 3 wt\%)

Dispersion of sepiolite in SEBS is quite good; there are few aggregates of particles especially when it is incorporated at $1 \mathrm{wt} \%$. Sepiolite shows a better dispersion than montmorillonite and a better adhesion with the matrix.

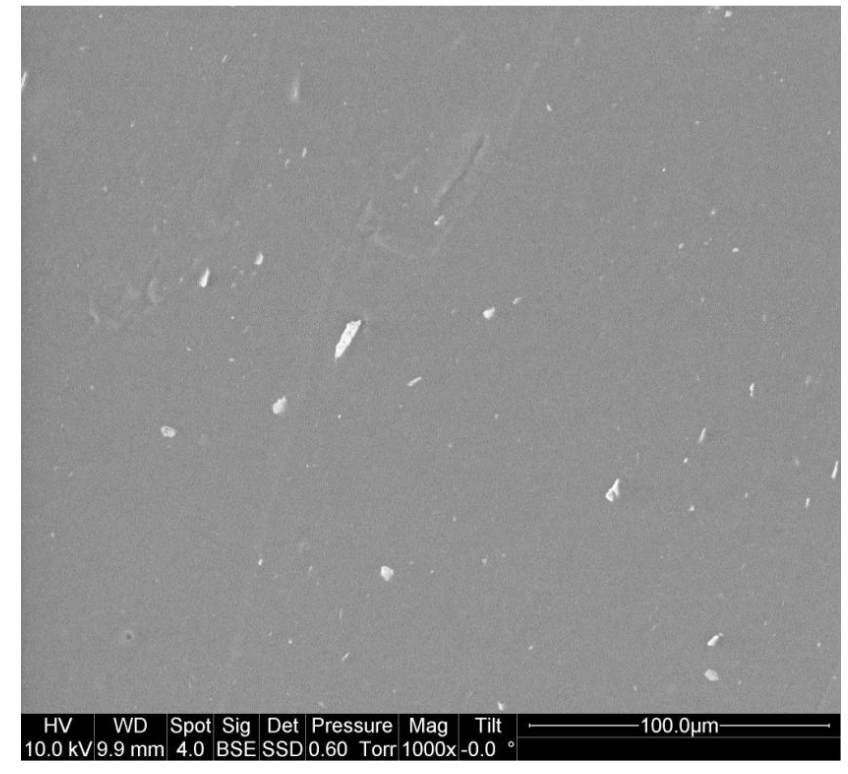

(a)

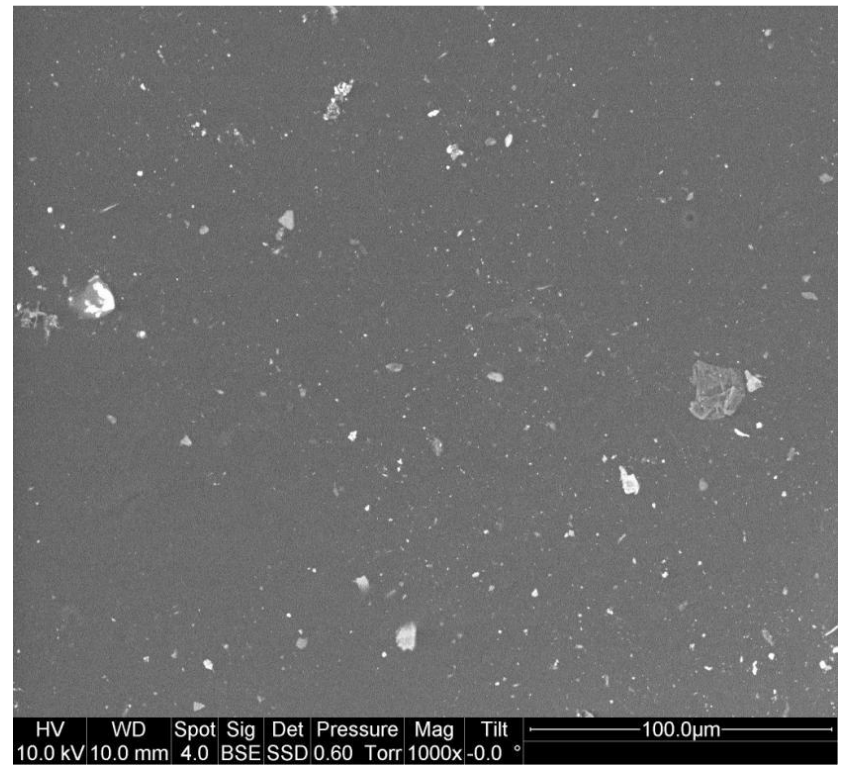

(b)

Figure 9. SEM pictures of SEBS / Aerosil® R202 (a: 1 wt\% ) (b: 3 wt\%)

Hydrophobic fumed silica is not well dispersed in SEBS; it does not show a good adhesion. Very big agglomerates can be seen in the formulation at $3 \mathrm{wt} \%$ incorporation. 


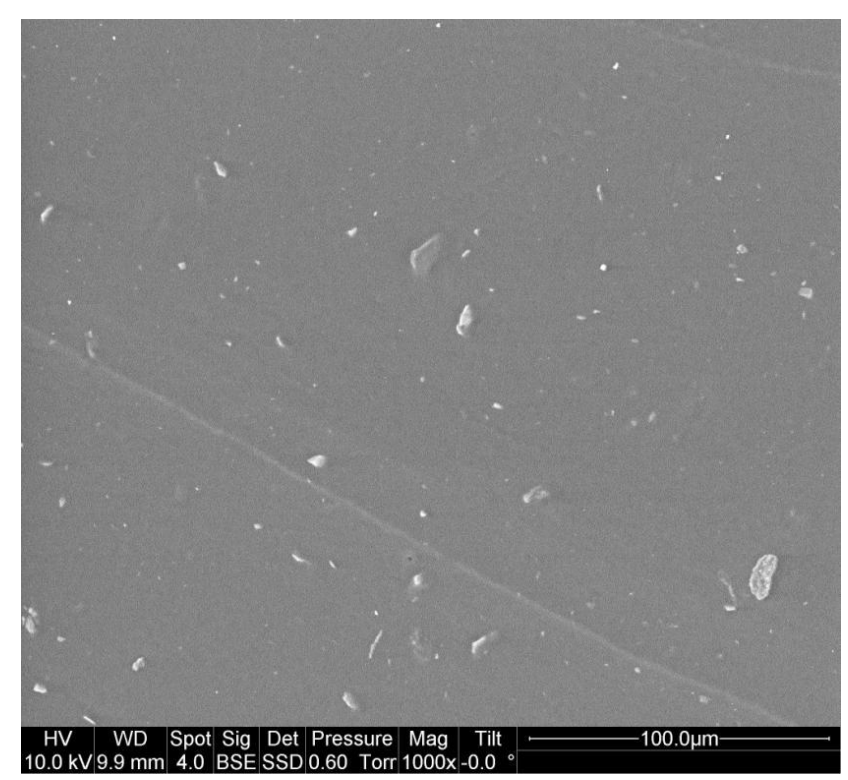

(a)

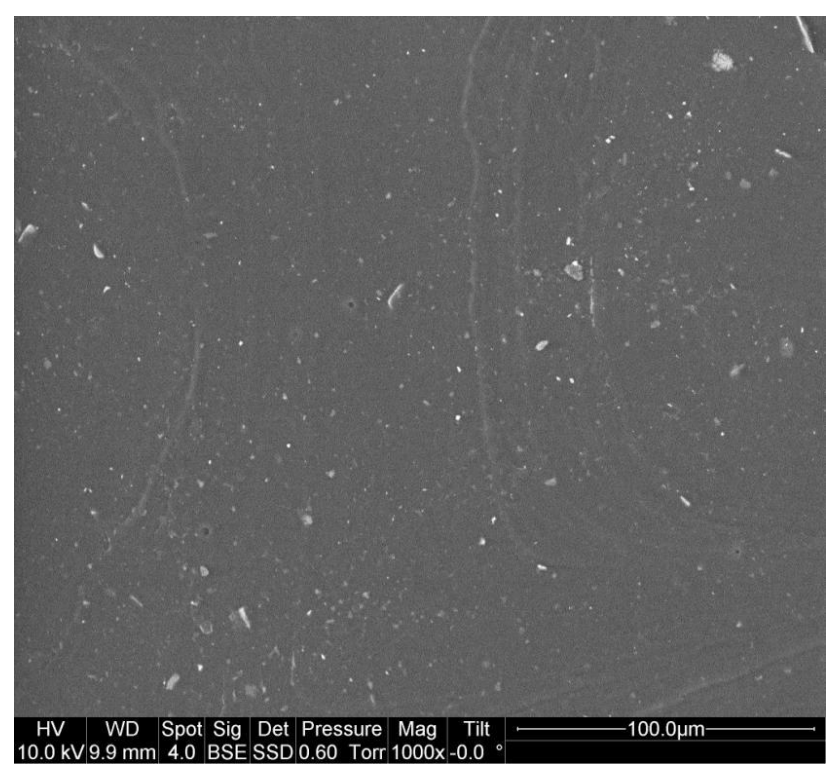

(b)

Figure 10. SEM pictures of compatibilized materials (a: SEBS / SEBS-g-MA / Cloisite® 30B 1wt\%) (b: SEBS / SEBS-g-MA / Aerosil@ 3001 wt\% )

In formulations containing SEBS-g-MA as compatibilizer, Cloisite ${ }^{\circledR} 30 \mathrm{~B}$ seems as well dispersed as in non compatibilized formulations. But hydrophilic silica seems much well dispersed in SEBS with SEBS-g-MA than hydrophobic silica in SEBS. Few agglomerates can be seen in Figure 10 (b).

Mechanical properties. SEBS formulations have been mechanically tested; mechanical properties have been represented as a function of the weight percentage of nano-particles for each kind of nano-particles. Tear strength of the SEBS formulations are shown in Figure 11, elongation at break in Figure 12, \%SR in Figure 13, \%VR in Figure 14 and the flow stress in Figure 15.

PU formulations were performed but they could not be tested because the tear strength test was not efficient since it behaved finally for these samples as a tensile test. The angular specimens were elongated till the limit value of the tensile device and the maximum force for rupture could not be determined. In order to get tear strength results, other standard tests using trapezoidal specimens are under study and results are pending.

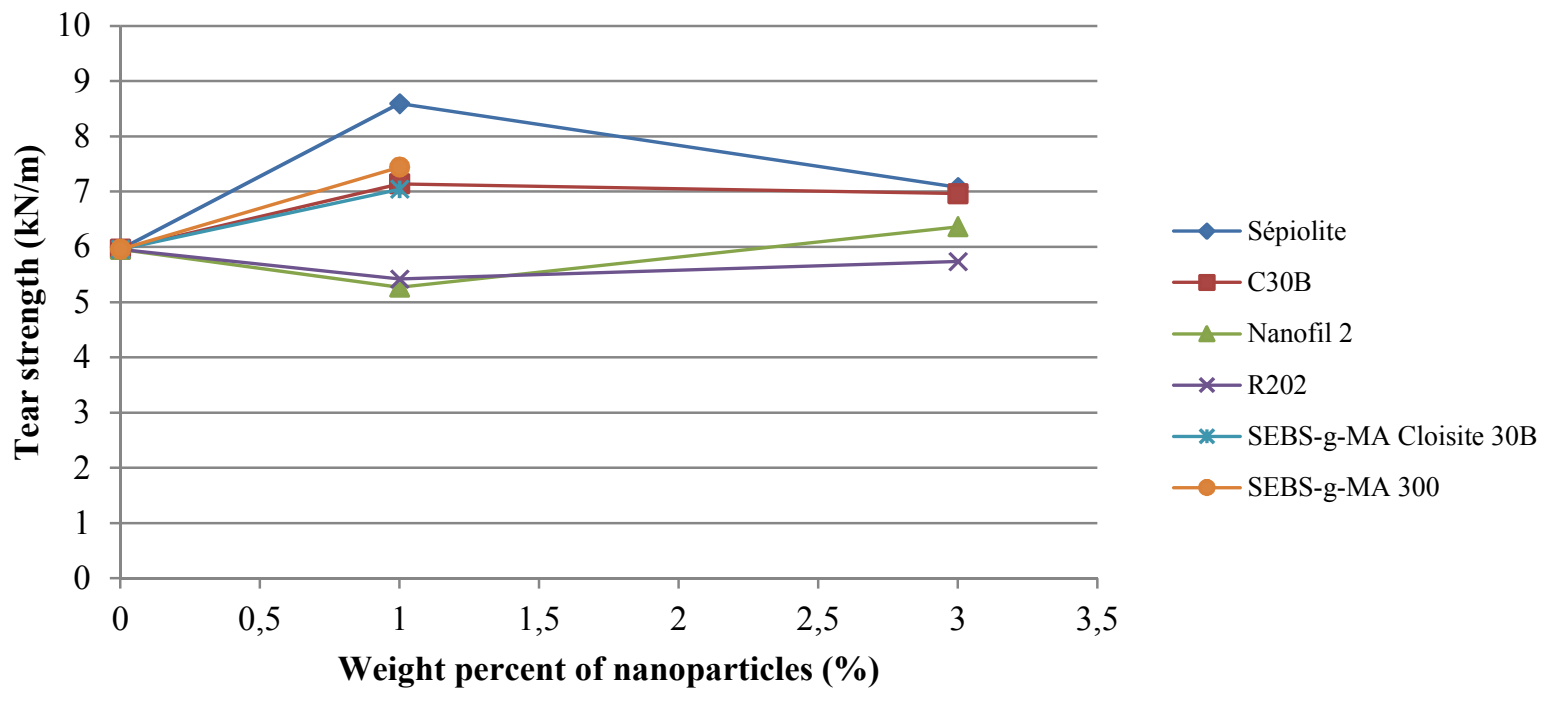

Figure 11. Tear strength of SEBS formulations as a function of nano-particles incorporation $(\mathbf{w t} \%)$ 


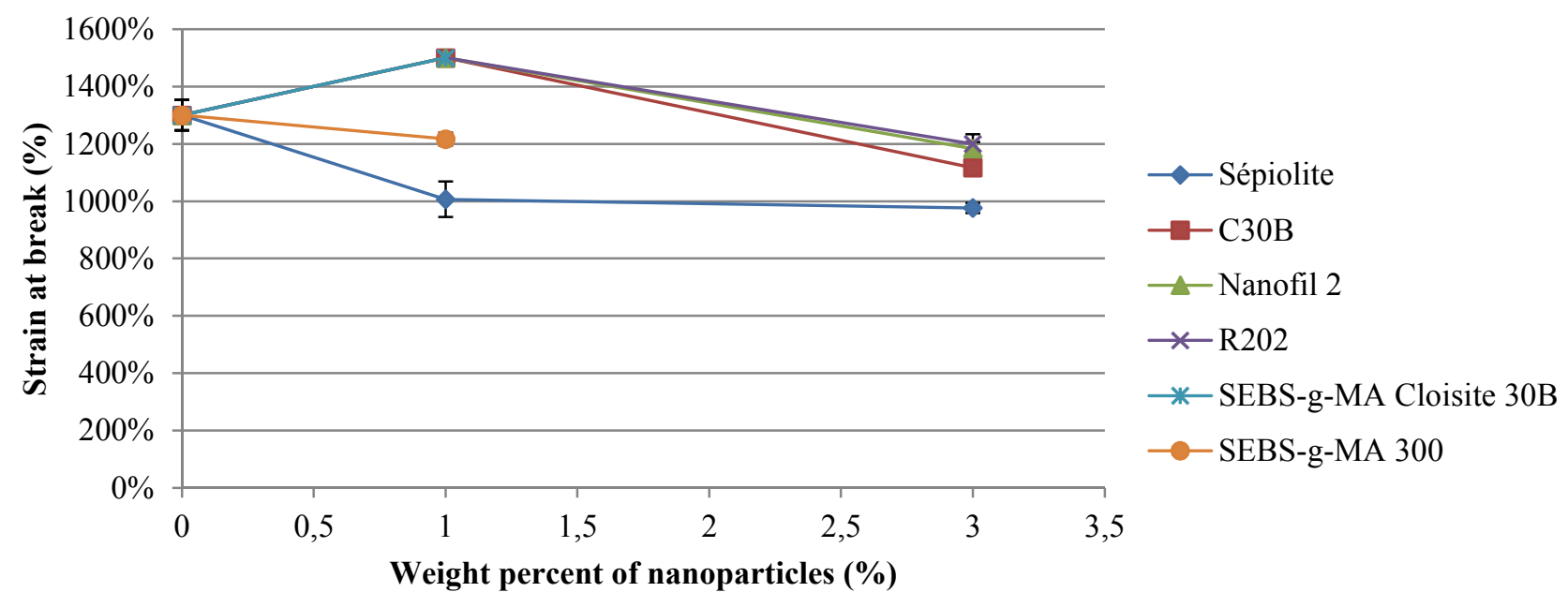

Figure 12. Strain at break of SEBS formulations as a function of nano-particles incorporation $(\mathbf{w t} \%)$

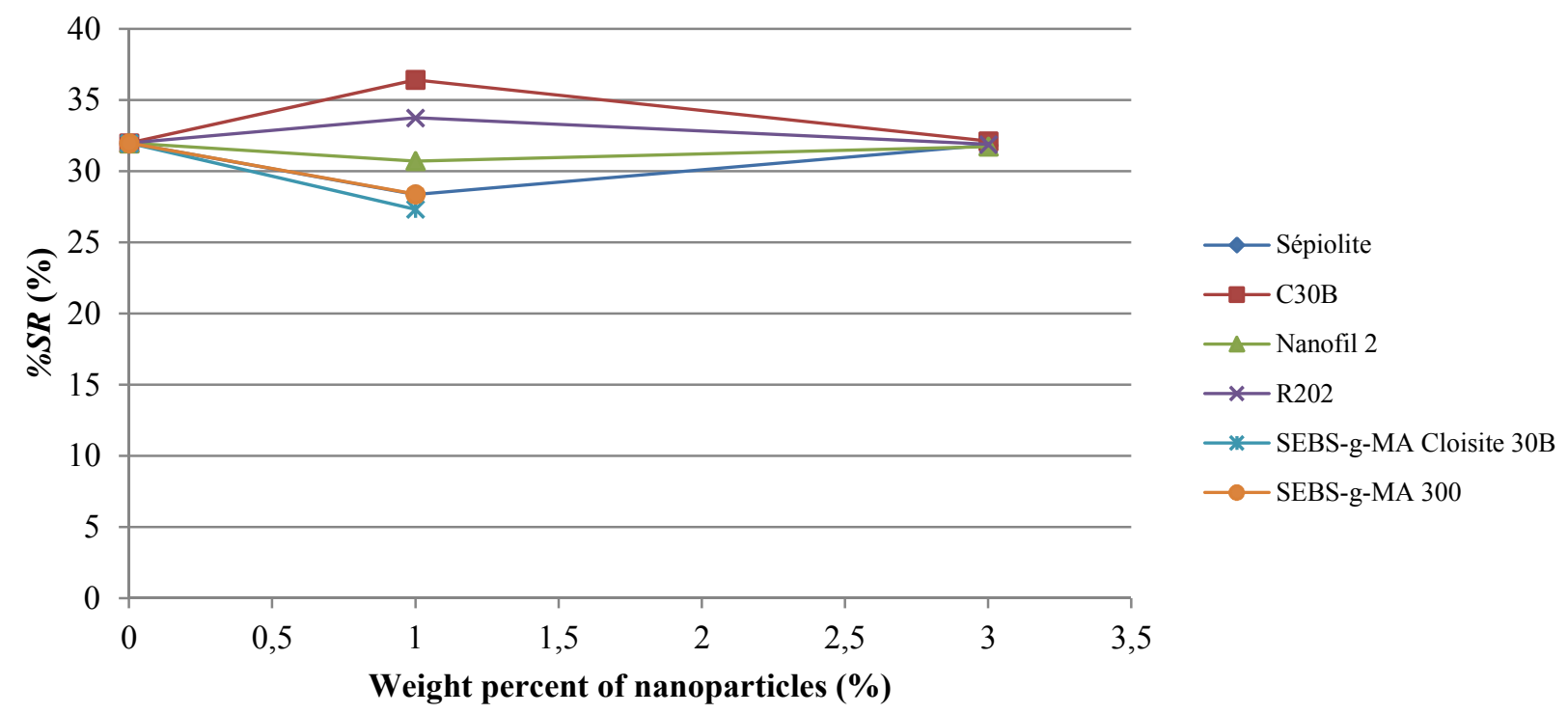

Figure 13. \%SR of SEBS formulations as a function of nano-particles incorporation (wt\%)

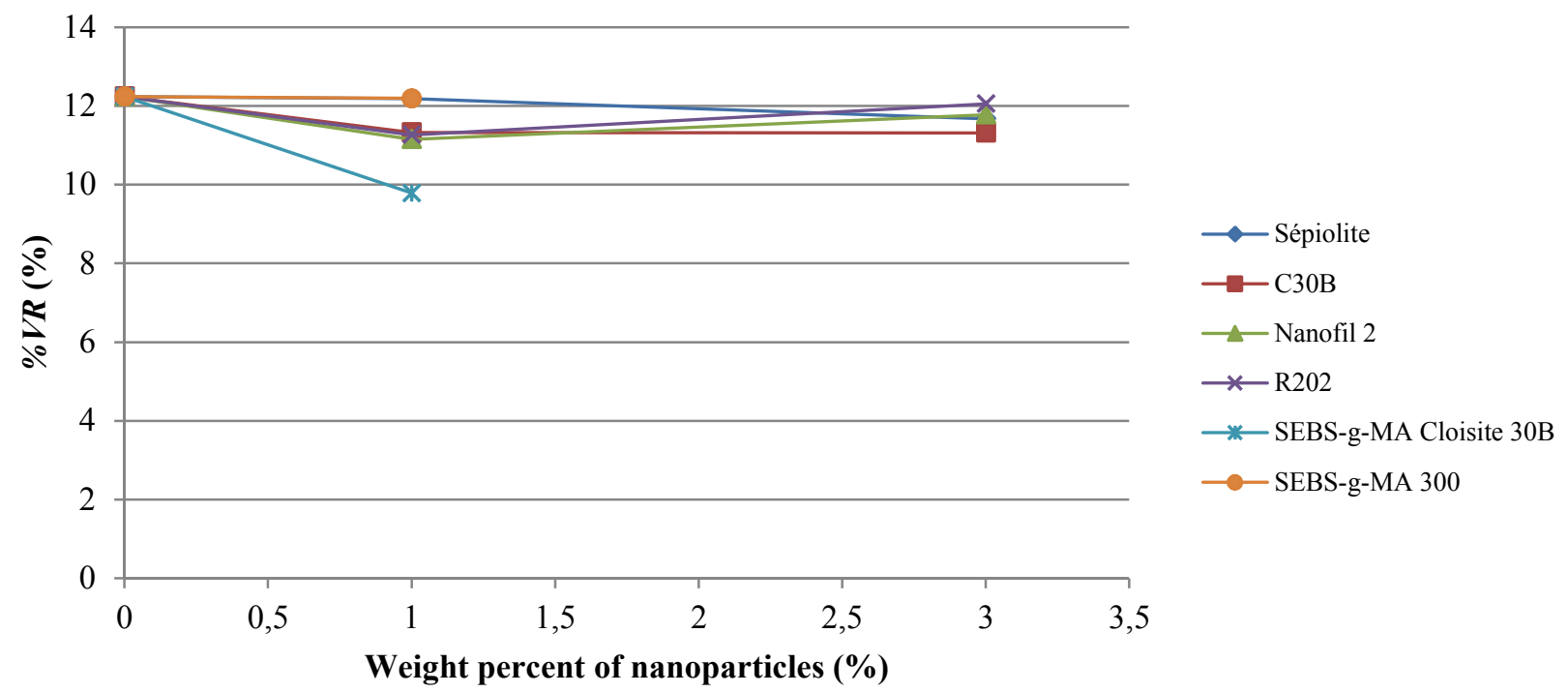

Figure 14. \%VR of SEBS formulations as a function of nano-particles incorporation (wt\%) 


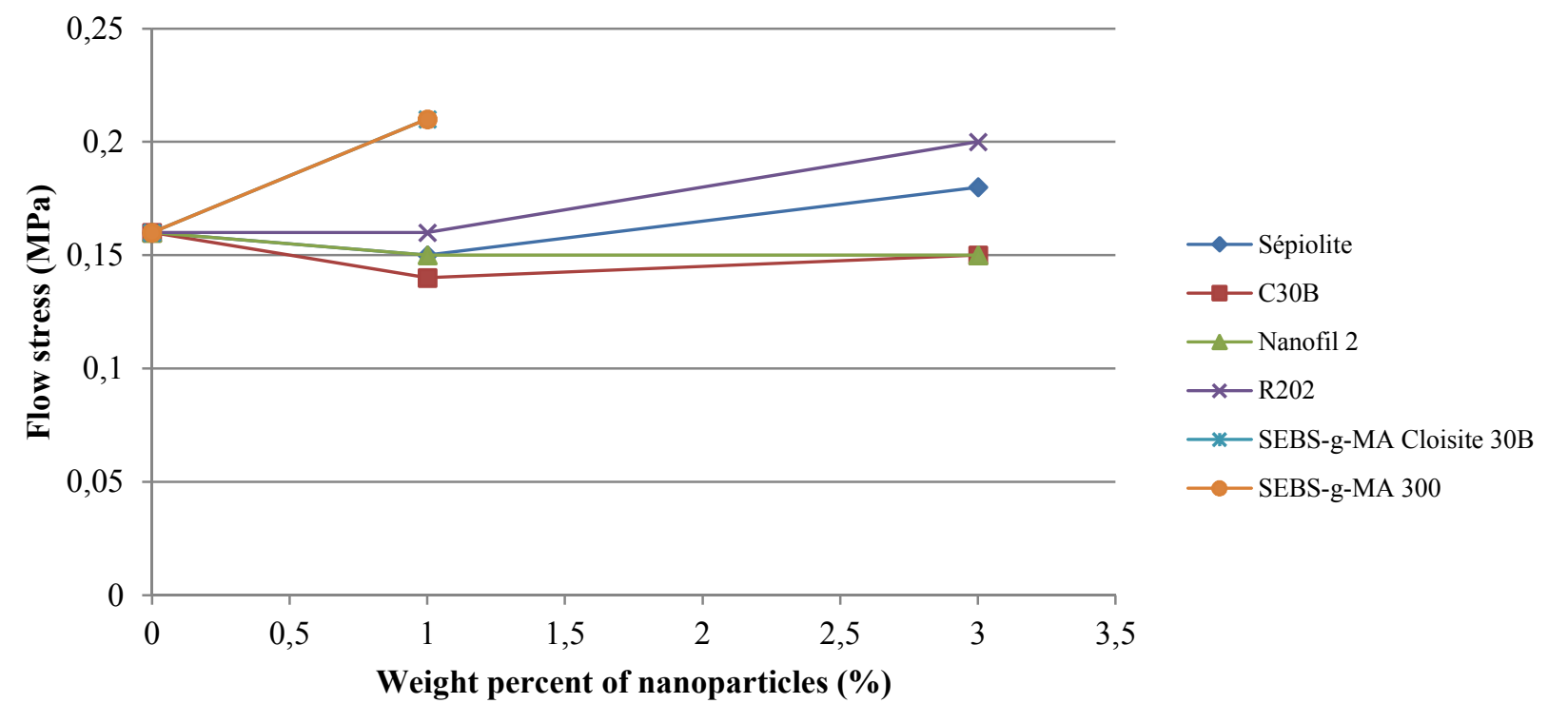

Figure 15. Flow stress of SEBS formulations as a function of nano-particles incorporation $(\mathbf{w t} \%)$

The incorporation of nano-particles has an impact on the tear strength of the SEBS. This strength is improved of a factor $1 / 3$ for sepiolite at a level of 1 weight percent incorporation as shown in Figure 11. One can notice that the best improvement occurs with the use of sepiolite, Cloisite ${ }^{2} 30 \mathrm{~B}$ and both materials compatibilized by SEBS-g-MA. For Nanofil ${ }^{2} 2$ and fumed hydrophobic silica, a decrease of toughness is observed, however this decrease is low. Different reason can explain these phenomena. Compatibilized materials contain SEBS-g-MA which is harder than SEBS (respectively 71 and 11 Shore A); it leads to an increase of the toughness of the material and as a consequence an increase of the tear strength. Materials with well dispersed nano-particles have a better tear strength than others; for example SEBS with sepiolite at $1 \mathrm{wt} \%$ incorporation (well dispersed) show enhanced tear strength properties in comparison with Sepiolite at $3 \mathrm{wt} \%$. Agglomerates create local stresses and fracture initiation under loading.

Figure 12 shows that strain at break of SEBS is highly modified by the incorporation of nanoparticles. Silicates and silica enhance this property to $1500 \%$ at $1 \mathrm{wt} \%$ incorporation then decrease it at $3 \mathrm{wt} \%$ incorporation, while sepiolite decreases the elongation at break to $1000 \%$.Again, on the whole a better dispersion of a filler lead to a higher strain at break. However, formulations which show the best improvement of tear strength are the one which have the worst properties of strain at break. (sepiolite and materials compatibilized with SEBs-g-MA)

Figure 13 and 14 show that nano-particles do not exhibit a significant impact on the stabilization and viscosity ratio $(\% V R$ and $\% S R)$ of the SEBS. These energetic parameters are mainly governed by the matrix, the incorporation levels are too low to change them considerably, except for the materials compatibilized with SEBS-g-MA ( $8 w t \%$ of SEBS-g-MA).

Flow stress is neither much affected by the incorporation of nano-particles. A low decrease of this flow stress is observed for sepiolite, silicates and hydrophobic fumed silica at a level of 1 weight percent and an increase is observed for these particles at a level of $3 \mathrm{wt} . \%$ (Figure 15). For the SEBS-g-MA compatibilized materials, the flow stress increase above $0.2 \mathrm{MPa}$ probably because of the increase of toughness created by addition of SEBS-g-MA.

The results obtained are antagonistic. Sepiolite at a level of 1 weight percent seems to be the best choice to increase the tear strength of SEBS, however this nanofiller is the worst in terms of strain at break. Conversely, Nanofil ${ }^{\circledR} 2$ and Cloisite ${ }^{\circledR} 30 \mathrm{~B}$ increase a lot the elongation at break but increase very weakly or decrease the tear strength of SEBS. 
Conclusion. Organomodified layered silicates and silicas have been incorporated in thermoplastic elastomers such as styrene-ethylene-butylene-styrene copolymers (SEBS) and polyurethanes (PU). The mechanical properties have been investigated with two mechanical tests: a tear strength test and a sequenced tensile test. The incorporation of nanoparticles in SEBS can lead to the improvement of some of the mechanical properties such as tear strength, elongation at break and stress flow. Nevertheless, antagonistic results can be noticed for these properties, since the best improvement of the tear strength is achieved with the use of sepiolite at a level of $1 \mathrm{wt} \%$ but at the expense of a low improvement of the elongation at break. The best improvement of the elongation at break is obtained using layered silicates but with a poor improvement or a decrease of tear strength.

\section{References.}

[1] G. Holden and C.R. Wilder, in Handbook of elastomers, edited by A.N. Bhowmick and H.L. Stephens, Chapter 11, Marcel Dekker Inc, New York (2001).

[2] A. Nashay and J.E. McGrowth, in Block Copolymers, Academic Press, New York (1977).

[3] S.K. De, in Thermoplastic Elastomers from Rubber-Plastics Blends, edited by A.N. Bhowmick, Horwood, New York (1990).

[4] J.E. Mark and B. Erman, in Science and Technology of Rubber, edited by F.R. Eirich, Academic Press, New York (1994).

[5] C.S. Schollenberg, in Handbook of elastomers, edited by A.N. Bhowmick and H.L. Stephens, Chapter 14, Marcel Dekker Inc, New York (2001).

[6] A. Usuki, Y. Kojima, M. Kawasumi, A. Okada, Y. Fukushima and T Kurauchi: Journal of Materials research Vol. 8 (1993) p. 1179

[7] A. Usuki, Y. Kojima, M. Kawasumi, A. Okada, Y. Fukushima and T Kurauchi: Journal of Materials research Vol. 8 (1993) p. 1185

[8] E.P. Giannelis: Journal of Advanced Materials Vol. 8 (1996) p. 29

[9] T. Lan and T.J. Pinnavaia: Journal of materials Science Vol. 29 (1994) p. 2274

[10]X. Wang, S.L. Pang, J.H. Yang and F.T. Yang: Transactions of Nonferrous Metals Society of China Vol. 16 (2006) p. 524

[11] Y.W. Chen-Yang, Y.K. Lee, Y.T. Chen and J.C. Wu: Polymer Vol. 48 (2007) p. 2969

[12] Y.I. Tien and K.H. Wei: Macromolecules Vol. 34 (2001) p. 9045

[13]T. Amornsakchai, B. Sinpatanapan, S Bualek-Limcharoen and W. Meesiri : Polymer Vol. 40 (1999) p. 2993

[14]L.A. Utracki: The Canadian Journal of Chemical Engineering Vol. 80 (2002) p. 1008 